\title{
BMJ Open Gender differences within the barriers to smoking cessation and the preferences for interventions in primary care a qualitative study using focus groups in The Hague, The Netherlands
}

\author{
Lieke Agathe Dieleman, Petra G van Peet, Hedwig M M Vos (D)
}

To cite: Dieleman LA, van Peet PG, Vos HMM. Gender differences within the barriers to smoking cessation and the preferences for interventions in primary care a qualitative study using focus groups in The Hague, The Netherlands. BMJ Open 2021;11:e042623. doi:10.1136/ bmjopen-2020-042623

- Prepublication history and additional material for this paper are available online. To view these files, please visit the journal online (http://dx.doi. org/10.1136/bmjopen-2020042623).

Received 17 July 2020 Revised 21 December 2020 Accepted 13 January 2021

D Check for updates

(c) Author(s) (or their employer(s)) 2021. Re-use permitted under CC BY-NC. No commercial re-use. See rights and permissions. Published by BMJ.

Department of Public Health and Primary Care, LUMC, Leiden, The Netherlands

Correspondence to Hedwig M M Vos;

h.m.m.vos@lumc.nl

\section{ABSTRACT}

Objectives This research aimed to provide a deeper insight into the gender-specific barriers to smoking cessation and gender-specific preferences for interventions in primary care, in order to contribute to better aligned cessation care for women.

Design Qualitative study using focus groups.

Setting Regularly smoking female and male adults were recruited from four different general practices in The Hague (The Netherlands).

Participants A total of 11 women and nine men participated. Participants included were regular smokers with a minimum age of 18 and sufficient command of the Dutch language, who were willing to talk about smoking cessation. Inclusion ended when saturation was reached for both women and men. Participants were selected by means of purposeful sampling, whereby looking at age, educational level and experience with quitting.

Results The main barriers to smoking cessation in women were psychological factors, such as emotion and stress, compared with environmental factors in men. Women indicated they were in need of support and positivity, and both women and men expressed the desire for assistance without judgement. Contrary to men, women were not drawn to restrictions and (dis)incentives.

Conclusion When counselling smokers, in women the focus should be on perceived internal problems, as opposed to more external obstacles in men. Contrary to men, female smokers seem to prefer non-coercive interventions, such as a group intervention offering support and positivity. Future research should focus on these gender differences, and how they could improve treatment in primary care.

\section{BACKGROUND}

Cigarette smoking is the leading cause of premature death and an important risk factor for chronic diseases, such as cancer and cardiovascular disease. ${ }^{1}$ Although the total number of smokers in the Netherlands has been decreasing over the past decades, the number of female smokers has declined slower than the number of male smokers.

\section{Strengths and limitations of this study}

- This study helps to develop a better understanding of gender differences in smoking cessation by comparing focus groups with women and men.

- This study used the intervention ladder to classify gender-specific preferences for interventions by their degree of pressure.

- This study provides more insight into severely addicted smokers, and gives recommendations for adjusting treatment in clinical setting.

- Additional individual interviews were conducted, as not enough male participants were simultaneously available to participate in focus groups. A mixedgender group was not included as a control, what could have promoted the reliability of this study.

- The study group was not fully representative for smokers in the Dutch population, as the average age in both groups was high and the level of education among female participants was relatively high. The number of quit attempts turned out to be nonquantifiable in both women and men, impairing us to match participants to addiction severity.

Although women and men attempt to quit smoking just as often, women appear to be $31 \%$ less successful. ${ }^{2}$ Yet, smoking cessation seems particularly important for women, as their health risks exceed those of men. Both the tobacco-attributed mortality and lung cancer incidence have been increasing in women, opposed to decreasing in men. ${ }^{3-5}$ The increase in lung cancer among women can be explained by their higher sensitivity to carcinogens, ${ }^{67}$ as well as the results of strategic actions by the tobacco industry by targeting women. ${ }^{8-10}$ Compared with nonsmokers, the relative risk of cardiovascular disease is $25 \%$ higher in female smokers than in male smokers. ${ }^{11}$ Also, smoking women have an increased risk of breast cancer, ${ }^{12} 13$ cervical cancer $^{14}{ }^{\text {infertility, }}{ }^{15}$ poor pregnancy 
outcomes, ${ }^{17} 18$ early menopause ${ }^{19}$ and osteoporosis. ${ }^{20} 21$ Although relatively few women are aware of these risks, ${ }^{22}$ these risks highlight the importance of improving cessation success rates in female smokers in particular.

Different explanations can be found for the lower success rates of smoking cessation in female smokers. First of all, the physical nicotine dependency is lower in women than men. ${ }^{23}$ This may seem contradictory, but women seem to experience higher mental and behavioural dependency, which might persist longer after cessation than physical nicotine dependency. Women metabolise nicotine faster than men, ${ }^{24}$ especially when using oral contraception. ${ }^{25}$ This might also explain why nicotine replacement therapy is less effective in women than in men in the same dosage. ${ }^{26}{ }^{27}$ Research has indicated that craving and nicotine reward might be positively associated with oestrogen levels. ${ }^{28} 29$

Another explanation can be found in the sociopharmacological model for tobacco addiction proposed by Leventhal, ${ }^{30}$ wherein the interaction between psychopharmacological and contextual factors is studied. This theory argues that social and environmental factors form greater barriers to women. ${ }^{31}$ For example, women are more often victims of sexual violence, ${ }^{32}$ which is related to substance use. ${ }^{33}$ Also, on average, women appear to have a lower income, ${ }^{34}$ and might, therefore, be less able to afford adequate care.

Moreover, gender differences seem to exist within the barriers smokers perceive towards cessation, and these might contribute to the varying success rates. Regarding smoking behaviour, men seem to smoke more often because of the stimulating effects of nicotine, while on average, women smoke more often out of habit or to regulate their mood. ${ }^{35}$ In addition, smoking in men seems to be more related to food, alcohol and smokers in the vicinity, compared with stress and craving in women. ${ }^{36}$ Although barriers related to stress and mood regulation and social factors seem to be common in both women and men, women on average seem to be affected by a greater number of barriers and distinct stress-related barriers. ${ }^{37}$ Other barriers that seem to be more prominent in women are sensory aspects, the lack of social support, ${ }^{37}$ and the fear of weight gain. ${ }^{38}$ Besides the previously mentioned role of sex hormones, mental health and personality patterns also seem to affect cessation and vary by gender. ${ }^{39}$ Pregnancy and parenthood, on the other hand, seem to have a positive effect on cessation, especially in women. ${ }^{40}$

In spite of these disparities between women and men, current care is not yet adjusted to such gender differences. This raises the question whether a gender-specific approach is required and how this should be brought into practice. ${ }^{41}$ Smoking women seem to consult their general practitioner (GP) twice as often as smoking men, ${ }^{42}$ which makes the GP a suitable healthcare professional to assist women with quitting. Research shows that women are more likely to use recommended cessation resources such as nicotine patch, varenicline and Smokers' Helpline than men, ${ }^{43}$ and might benefit more from non-nicotine or behavioural interventions. ${ }^{39}$ Women-specific programmes are limited and show inconsistent outcomes, but might help to reduce barriers to treatment entry. ${ }^{44}$ This study aimed to provide a deeper insight into the gender-specific barriers to smoking cessation and gender-specific preferences for interventions, in order to contribute to better aligned cessation care for women.

\section{METHODS}

\section{Population}

Qualitative research was conducted, using focus groups with smoking women and men recruited in primary care. The total number of participants was depending on when saturation was reached, while pursuing diversity. Participants that met the inclusion criteria were regular smokers with a minimum age of 18 and sufficient command of the Dutch language, who were willing to talk about smoking cessation. Willingness to actually quit smoking was not a requirement, since the barriers participants perceived towards actually wanting to quit smoking were subject of investigation.

\section{Procedure}

Participants were recruited from four general practices located in the Dutch city of The Hague during October 2019 and November 2019. General practices and participants were selected by means of purposeful sampling. Criteria for diversity were age, educational level as a proxy for socioeconomic status and experience with quitting assessed by the number of attempts. Suitable participants were approached by their GP or practice nurse during consultation, or by telephone based on information about smoking in electronic medical records. Data analysis started immediately following each focus group. When the earlier mentioned criteria for diversity were guaranteed and no new information was obtained from the focus groups, it was concluded that saturation was be reached. An additional interview was conducted for final confirmation. For further details on the recruitment of participants, see figure 1.

All focus groups and interviews were audiorecorded. Participants signed informed consent before participation. Participants could withdraw from the study at any moment.

\section{Focus groups}

Focus groups were preferred over individual interviews, because interaction allows participants with different opinions to deepen their opinion and develop arguments. Separate groups were formed for women and men, with a maximum of six participants. Focus groups had a maximum duration of 2 hours and took place at locations in the neighbourhood, such as community centres and care institutions.

A routing (see online supplemental appendix 1) was established based on gender sensitive aspects described in the literature. The main subjects were the benefits 


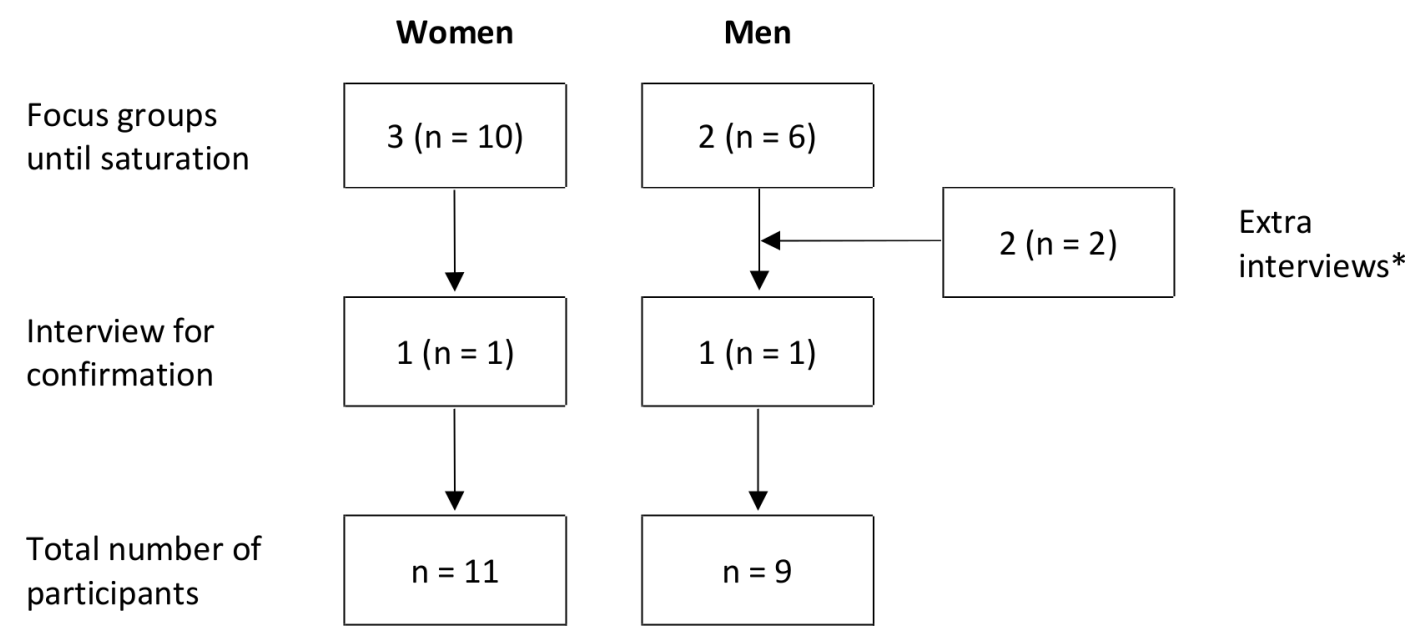

Figure 1 Recruitment of female and male participants. *Extra interviews were conducted when not enough participants were able to attend the focus groups.

of smoking, the barriers to smoking cessation and the possible interventions. After the first focus group, the routing was updated by adding the disadvantages of smoking and the knowledge of or experience with gender differences in smoking cessation. Under the guidance of a moderator $(\mathrm{PGvP})$, a GP experienced in leading focus groups, participants were asked to exchange ideas about these subjects. The two researchers (HMMV and LAD) were present during the focus groups to take field notes. The moderator and researchers are all female.

\section{Data analysis}

Data were analysed thematically using an inductive approach. ${ }^{45}$ The transcripts obtained from the focus groups and interviews, were anonymised and coded independently by two researchers (HMMV and LAD) to increase reliability. Both researchers freely coded all relevant information for women and men separately, and themes were derived from the categorised codes for every main subject. The classification of codes was discussed by the researchers (HMMV, LAD and PGvP), as well as the subsequent differences between women and men. Compatible codes were grouped and discussed, and eventually five main themes could be identified. The intervention ladder, which organises ways to promote public health from least to most coercive, was used to classify interventions. ${ }^{46}$ Atlas.ti (V.7.5.18) was used to process and analyse data.

\section{Patient and public involvement statement}

Study participants received a report of the study and after the first focus group we adapted the routing based on experiences and interests of the participants.

\section{RESULTS}

\section{Sample}

Saturation was reached at a total of 20 participants (participant 1-20), of which 11 were women. Table 1 shows the characteristics of the participants. Compared with all smokers in the Netherlands, the average age in both groups was high. The level of education among male participants was representative for smokers in the Netherlands, but relatively high among female participants. The exact number of quit attempts turned out to be nonquantifiable, as most participants did not remember the exact number. However, based on the duration of smoking and the estimated overall large number of quit attempts among participants, we concluded that most participants included in our study were severely addicted smokers.

\section{Advantages and disadvantages}

First, participants were asked about the advantages and disadvantages of smoking, in order to get a better understanding of their motives to smoke or quit. Regarding the advantages of smoking, both women and men mentioned that smoking provided relaxation, played a connecting

Table 1 Participant characteristics $(n=20)$

\begin{tabular}{|c|c|c|c|c|c|c|c|c|c|}
\hline \multirow[b]{2}{*}{ Sex } & \multirow[b]{2}{*}{$\mathbf{N}$} & \multicolumn{5}{|c|}{ Age in years (n) } & \multicolumn{3}{|c|}{ Educational level* (n) } \\
\hline & & 20-39 & $40-49$ & $50-59$ & $60-69$ & $70-79$ & Low & Middle & High \\
\hline Female & 11 & 1 & 3 & 5 & 1 & 1 & 3 & $6 \dagger$ & 1 \\
\hline Total & 20 & 1 & 6 & 7 & 4 & 2 & 7 & $9+$ & 3 \\
\hline
\end{tabular}

${ }^{*}$ The educational level is based on Statistics Netherlands (CBS) criteria: https://www.cbs.nl/nl-nl/artikelen/nieuws/2013/40/onderwijsniveaubevolking-gestegen/onderwijsniveau.

†The educational level of one female participant is missing. 
role and improved concentration. In addition, both women and men enjoyed the taste of cigarettes, as well as the activity and habit of smoking. Smoking also prevented weight gain in both women and men.

Regarding the disadvantages of smoking, both women and men experienced physical complaints. Also the tobacco smell for others was considered a disadvantage in both women and men, as well as the rising costs, and increasing criticism. On top of that, both groups felt they lost time and structure due to smoking. The only difference identified was the feeling of shame among women, compared with guilt in men as they set a bad example.

\section{Barriers and interventions}

These advantages and disadvantages of smoking led to the barriers to cessation. Once these were identified, the groups moved to finding possible interventions. Five main themes emerged from the data obtained on the barriers and interventions: psychological factors, perception on smoking cessation, motivation and selfefficacy, physical factors and external factors. Gender differences and similarities were found, which will now be discussed.

\section{Psychological factors}

A major barrier to smoking cessation, particularly prominent in women, was formed by emotional and stressful events.

Tension, just stress. ... Yes, difficult situations. And then you seek comfort in your cigarette. ... If I hadn't smoked, I might have grabbed a bag of potato chips or some chocolate instead (participant 13 - woman).

Women also dreaded the mood changes that followed after cessation, depressive symptoms in particular. Both women and men could become more irritable, resulting in the environment encouraging them to start smoking again. In addition, some women previously had felt like they lost their identity, as well as their freedom.

When I quit smoking, I always think: I have lost my freedom. However, that doesn't make sense, because you are addicted, so actually you have no freedom at all (participant 9-woman).

For women, these psychological barriers created the need for a buddy who could provide support, whereby positivity was important. An individual approach, adapted to personal problems, could be helpful for both women and men. Women and men both felt like they could benefit from quitting together with someone.

It helped me that he [a friend] didn't do it either. Because when you suffer together, your misery is cut in half. ... A sense of responsibility: you don't do it, so neither do I. We made an agreement, so I will stick to that (participant 4-woman).
Perception on smoking cessation

Both women and men felt much resistance to being forced to quit smoking by family or doctors, as well as to antismoking campaigns. Participants felt like they were already aware of the risks and consequences, and as a result, both pressure and antismoking campaigns had an opposite effect.

I think the more you are forced to quit, the more you will rebel, the more difficult it gets, the more you will smoke. Anti-smoking towards a smoker, ... [moderator: 'That won't help?'] No, you are already aware of those stories' (participant 5-man).

Quitting smoking meant for most participants they would have to give up a habit they had grown up with. Cigarettes were a part of life, connected to drinking a cup of coffee or eating a meal. Quitting also resembled to possibility of relapse, what made especially women feel weak.

'If you don't succeed repeatedly, you think: damn it! You get angry with yourself. ... I get so tired of myself that I am so weak' (participant 13-woman).

These barriers created the need for an intervention without coercion and judgement among both women and men, which should also allow room for relapse. Hereby, voluntary participation and the understanding of someone who had suffered the same were important.

'I notice that now we are talking about it so casually, by not saying: you have to, I think to myself: is that the motivation for quitting? Becoming aware. You are always aware, but by talking about it casually, it has more impact on me than saying: you have to quit' (participant 12-woman).

Lastly, both women and men expressed the need for recognition and treatment of smoking as a severe addiction. As examples, an 'alcoholics anonymous (AA) for smokers' and a clinic for admission were mentioned.

\section{Motivation and self-efficacy}

Both women and men were held back by the lack of motivation, which could be enhanced by thoughts and excuses justifying smoking.

You are aware that it's bad, but you do it anyway. There is so much you are not allowed to do, and then I think: stop whining! If I wouldn't have smoked my whole life, I would die anyway (participant 12-woman).

Women could also lose their motivation when they had insufficient perspective on a future without cigarettes. Some men on the other hand, lost their motivation as cigarettes were too tempting, causing them to relapse completely after one cigarette. Both women and men, especially those with many failed attempts, also experienced low self-efficacy: a low confidence in their own ability to quit smoking permanently. 
In order to increase motivation and self-efficacy, both women and men felt they could profit from knowledge about addiction, and from a better perspective on a future without cigarettes.

You need people who inspire you, who tell you they feel better. And you also see they look better since they have stopped smoking. ... I need that person who relapses in order to remind myself where I came from, and I need those people who are further than me to help me move in that direction (participant 19-man).

Female and male participants that were already motivated, thought a buddy with the same experience could help to maintain their motivation and alertness. Moreover, most participants considered volunteering as a buddy themselves after quitting, helping themselves to stay motivated. Furthermore, men might benefit from introducing financial incentives or other forms of reward.

\section{Physical factors}

The lack of physical complaints, as well as the lack of physical improvement after quitting, formed barriers to both women and men when attempting to quit smoking permanently. Hereby, participants mentioned that the severe physical consequences caused by smoking, compared with other addictions, often occur too late. In addition, both women and men had perceived side effects of medication used to help them quit during previous attempts. Finally, both women and men dreaded weight gain, as well as the withdrawal symptoms that could occur after quitting. Hereby, craving was especially important in women and could last for months.

It was like: constantly grumpy, a constant desire, almost going crazy. I just could kill someone because I wanted a cigarette so bad (participant 18-woman).

These physical barriers in both groups enhanced the need for feedback on physical improvement. A carbon monoxide metre appealed to some participants, as it could confirm it was indeed better to quit smoking. Female and male participants also thought a sports programme, possibly with fellow quitters, could help them to experience physical improvement. Finally, both women and men expressed the wish for medication to alleviate withdrawal and prevent weight gain, without any side effects.

\section{External factors}

External factors formed barriers especially in men. For example, the large availability of cigarettes in the Netherlands caused a low threshold for buying cigarettes after quitting in men. Another major barrier to men was the combination of cigarettes with social activities and alcohol.

It's a habit actually, when you pick up a cigarette (participant 5-man). Yes, also when you get a drink. A drink without a cigarette, I don't mind for it (participant 6-man). No, they go together, without thinking (participant 5-man).

Both women and men were influenced by other smokers in their surroundings, and women experienced the lack of support as barrier to quitting permanently.

Unlike women, men felt they could benefit from the government banning cigarettes completely, as well as increasing the price of cigarettes significantly.

The essence of the story is the opportunity. ... If it's not there, you won't miss it (participant 16-man).

Furthermore, both women and men expressed the need for clinics, where provocative situations could be avoided and distraction could be offered during admission. Also an experienced buddy could offer help: women needed someone who could offer support, while men preferred someone who could pick up the phone directly when they had the urge to smoke.

\section{Analysis}

An overview of the gender differences is shown in figure 2. The advantages and disadvantages of smoking led to barriers that were experienced during cessation. This resulted in ideas and preferences regarding interventions to overcome these barriers. Remarkable was that women seemed to experience more internal obstacles, such as stress and craving, compared with more external barriers in men, such as the social environment and alcohol. For women, this resulted in a need for emotional support and positivity, and resistance towards coercive measures and judgement. For men support should be focused on social aspects, temptation and rewards. Most participants, both women and men, indicated a preference for a group intervention tailored to these gender-specific barriers.

The obtained information on gender differences within the possible forms of support was analysed by using the intervention ladder (see table 2). Interventions further up the ladder ask for a stricter approach by the government, and seem to be favoured more by smoking men than women. Female smokers seem to prefer an intervention that enables lifestyle change and meanwhile enhancing autonomy. This could be provided through a group intervention tailored to such gender differences. Contrary to men, restrictions and (dis)incentives imposed by the government might not have a positive effect on women.

\section{DISCUSSION \\ Summary}

This qualitative study attempted to identify genderspecific barriers to smoking cessation, as well as the subsequent preferences for interventions in primary care for women. Five main themes emerged, whereby internal barriers, such as stress and craving, turned out to be more prominent in women, while external barriers, such as the high availability of cigarettes and social aspect of smoking, were more common in men. Women seemed 
BARRIERS

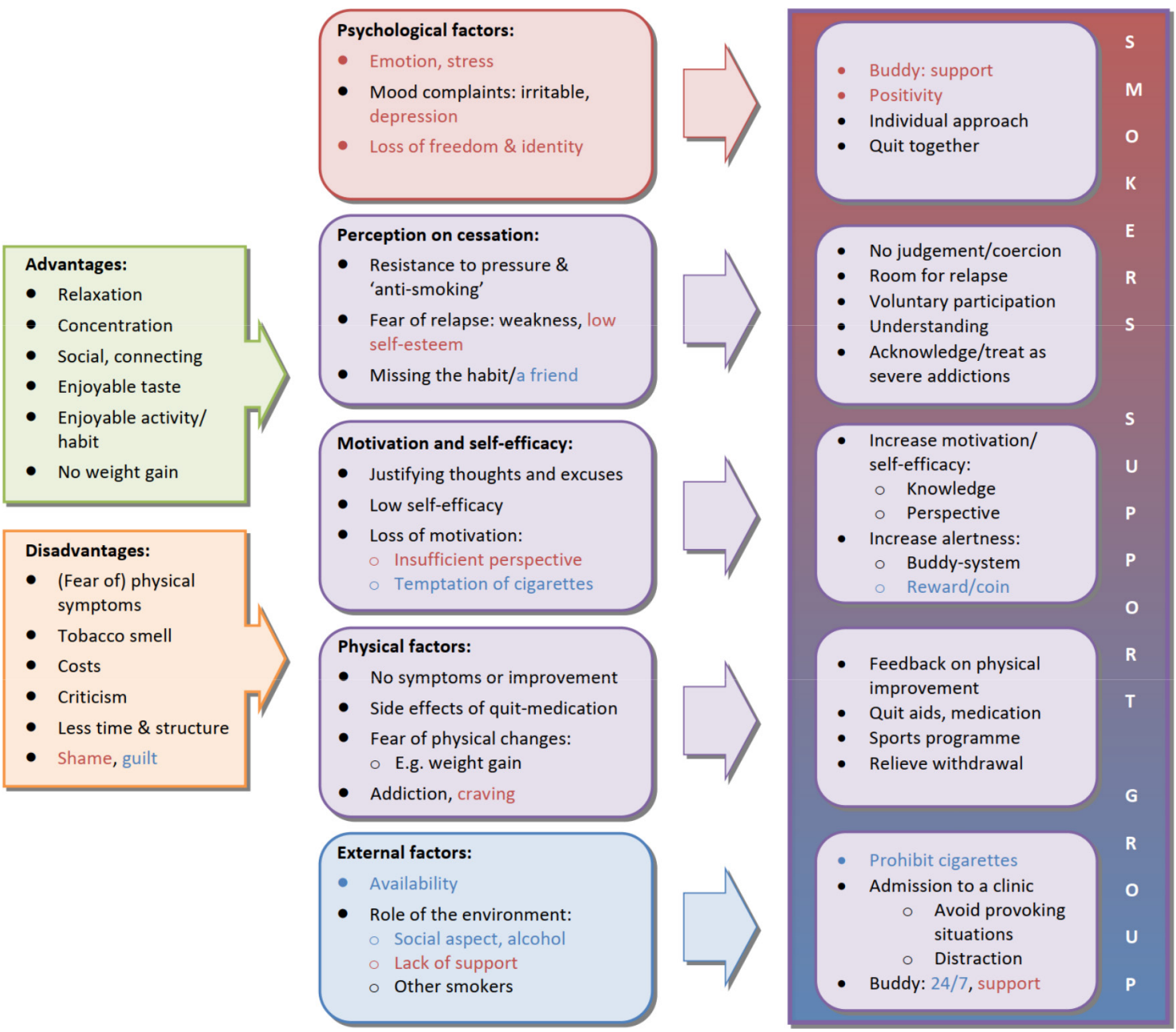

Figure 2 An overview of the results divided into five main themes. Left to right: the advantages and disadvantages of smoking led to barriers to cessation, which resulted in potential helpful interventions and ultimately in a new concept. top to bottom: themes predominant in women (red) and themes predominant in men (blue).

to prefer a group intervention with attention to and support of internal obstacles, whereby judgement and coercion could be counterproductive. Besides talking about smoking in a positive manner, women could offer each other support, and exchange knowledge and experiences. Within a group intervention, women also seemed to desire room for relapse and the support of a buddy with the same experience. Most participants wished to

Table 2 Classification of the interventions using the intervention ladder, categorised from least to most coercive measures, with themes predominant in women (red) and men (blue)

\begin{tabular}{lll}
7 & Eliminate choice & Prohibit cigarettes \\
6 & Restrict choice & Reduce cigarette availability \\
5 & Guide choice through disincentives & Increase costs of cigarettes \\
4 & Guide choice through incentives & Introduce rewards for quitting smoking \\
3 & Guide choice through changing the default policy & Enable rehab clinic for smokers \\
2 & Enable choice & Participate in a group intervention, offering support and positivity \\
& & Provide feedback on physical improvement, for example, sports \\
& & Programme \\
1 & Provide information & Relieve withdrawal, for example, quit aids/medication \\
0 & Do nothing or monitor the current situation & Quit without help \\
\hline
\end{tabular}


become a buddy themselves after achieving cessation, in order to maintain alertness.

It was remarkable that participants indicated the need for an intervention that would be similar to the focus group they were now participating in. Talking about smoking without the objective to quit was crucial. During the focus groups, a transformation was observed from initially unwilling to quit to considering quitting, as well as initially being determined to quit alone to developing the wish for a group. Talking about smoking casually and without pressure and judgement seems to be an important factor in a group intervention as described by participants. Moreover, the need for recognition and treatment of smoking as a severe addiction appeared to be strong. An AA and rehabilitation clinic for smokers were hereby mentioned as examples.

\section{Comparison with literature}

In the light of gender-specific barriers to smoking cessation, several studies pointed out the role of stress and craving in women. ${ }^{47} 48$ A negative affect in women seems to result in more craving than in men. ${ }^{49}$ Also, women seem to experience greater relief when resuming smoking after short abstinence, ${ }^{50}$ what might contribute to women relapsing more often than men. Therefore, attention to stress and craving seems important when counselling female smokers, what is confirmed by a study by Weinberger $e t a l^{\tilde{1}}$

External factors on the other hand seem to form greater barriers in men. This reflects earlier research, which shows that men on average benefit more from social control when quitting smoking. ${ }^{52}$ Recent research shows that women might benefit from quitting together with a partner, ${ }^{53}$ although older literature reports controversial results. ${ }^{54}$ When looking further into the role of the environment, research shows that disapproval of others and the feeling of shame might increase motivation to quit. $^{55}$ Within our study group, however, antismoking criticism proved to be counterproductive in both women and men, as well as causing shame in women. This difference might be explained by our specific study group, mostly consisting of severely addicted smokers. The urge for support without judgement was clearly present in this group, confirming the results of a previous study by Minian et a ${ }^{\tilde{6}}$

Unlike previous research, ${ }^{3857}$ we found little difference between women and men in terms of weight gain and no participants were interest in counselling by a dietician. In addition, we found a strong need for treating smoking as other severe addictions, such as for alcohol and drugs. Dutch doctors specialised in addiction have recently expressed similar signals about the importance of clinics for smokers. ${ }^{58} \mathrm{~A}$ buddy system has proven effective in the treatment of these addictions. ${ }^{59} \mathrm{~A}$ buddy system seems feasible, as most participants wished to stay involved as buddy after quitting.

With regard to the intervention ladder, we found that coercive measures, such as a ban on cigarettes, might have a more positive impact on male than female smokers. Up until now, research on involuntary tobacco abstinence and cessation rates is mainly conducted among smokers in the US Air Force, wherein no gender differences were found.$^{60}$ However, a ban on cigarettes resulted in the intention to start smoking twice more often in previously non-smoking women than men. ${ }^{61}$

The strength of this study is the use of focus groups, comparing women to men. This helps to develop a better understanding of gender differences in smoking cessation and thereby to better align interventions in primary care. We used the intervention ladder to classify these ways of promoting public health by the degree of coercion needed. Another strength of this study is the fact that we can provide advice for a specific group of smokers for which current treatment options seem to be too limited, namely severely addicted smokers. As it turned out, they were most willing to participate in the focus groups.

A possible limitation to our research is the fact that some additional individual interviews had to be conducted among men, as men seemed less willing or able to participate. In addition, the study group appeared to be not fully representative for smokers in the Dutch population in terms of age and educational level. Moreover, the number of quit attempts turned out to be nonquantifiable in both women and men, impairing us to match participants to addiction severity. Therefore, our results may not be applicable to all smokers. Finally, we studied gender-specific focus groups which might confound the results given the focus on sex differences. A mixed-gender group as a control could have promoted the reliability of our study.

\section{Clinical implications}

Our findings contribute to improving our understanding of the role of gender differences in cessation care, and thereby opening the door to a healthcare better aligned to these gender disparities. Group interventions adjusted to gender-specific barriers and preferences might form a feasible option. Within this study group of severely addicted smokers, both the need for and interest in such an intervention were expressed. Although women and men seemed to prefer interventions at different ends of the Intervention Ladder, they also showed some similar interests. For example, both women and men seemed to prefer a group intervention over pharmacotherapy. This raises the question whether separate treatment is needed. Several women indicated they could benefit from the presence of men, but some were afraid they would be less able to express emotions. Yet, this seems to be an area of attention when supporting women with cessation. This knowledge might also help clinicians in their daily practice, as they can be attentive to such gender differences when counselling smokers.

\section{Implications for future research}

Further exploration of gender-specific barriers and preferences is needed. Additionally, future research should 
investigate if attention to these gender differences could improve treatment in primary care, and how genderspecific treatment could be implemented. The necessity of separate over mixed-gender treatment should also be explored.

\section{Twitter Hedwig M M Vos @HedwigVos}

Contributors HMMV and PGVP contributed substantially to the conception and design of the study; LAD and HMMV contributed to the acquisition of participants. HMMV and LAD included patients and were present during the focus groups. PGvP guided the focus groups. All three authors contributed to the analysis and interpretation of the data for this study. LAD together with PGvP and HMMV drafted the paper and revised it critically for important intellectual content. All three authors approved of the final version to be published. All authors agreed to be accountable for all aspects of the work and ensure that questions related to the accuracy or integrity of any part of the work are appropriately investigated and resolved.

Funding The study is funded by ZonMW, The Netherlands Organisation for Health Research and Development, grant number: 849600001.

Competing interests None declared.

Patient consent for publication Not required.

Ethics approval The study was approved by the medical research ethics committee of Leiden University Medical Centre (LUMC).

Provenance and peer review Not commissioned; externally peer reviewed.

Data availability statement All data relevant to the study are included in the article or uploaded as online supplemental information. The protocol is available (in Dutch).

Supplemental material This content has been supplied by the author(s). It has not been vetted by BMJ Publishing Group Limited (BMJ) and may not have been peer-reviewed. Any opinions or recommendations discussed are solely those of the author(s) and are not endorsed by BMJ. BMJ disclaims all liability and responsibility arising from any reliance placed on the content. Where the content includes any translated material, BMJ does not warrant the accuracy and reliability of the translations (including but not limited to local regulations, clinical guidelines, terminology, drug names and drug dosages), and is not responsible for any error and/or omissions arising from translation and adaptation or otherwise.

Open access This is an open access article distributed in accordance with the Creative Commons Attribution Non Commercial (CC BY-NC 4.0) license, which permits others to distribute, remix, adapt, build upon this work non-commercially, and license their derivative works on different terms, provided the original work is properly cited, appropriate credit is given, any changes made indicated, and the use is non-commercial. See: http://creativecommons.org/licenses/by-nc/4.0/.

ORCID iD

Hedwig M M Vos http://orcid.org/0000-0002-3436-3892

\section{REFERENCES}

1 World Health Organization. Global health risks: mortality and burden of disease attributable to selected major risks, 2009.

2 Smith PH, Kasza KA, Hyland A, et al. Gender differences in medication use and cigarette smoking cessation: results from the International tobacco control four country survey. Nicotine Tob Res 2015;17:463-72.

3 Thun M, Peto R, Boreham J, et al. Stages of the cigarette epidemic on entering its second century. Tob Control 2012;21:96-101.

4 Lortet-Tieulent J, Renteria E, Sharp L, et al. Convergence of decreasing male and increasing female incidence rates in major tobacco-related cancers in Europe in 1988-2010. Eur J Cancer 2015;51:1144-63.

5 Karim-Kos HE, Janssen-Heijnen MLG, van lersel CA, et al. The beginning of the end of the lung cancer epidemic in Dutch women? International Journal of Cancer 2008;123:1472-5.

6 Pauk N, Kubík A, Zatloukal P, et al. Lung cancer in women. Lung Cancer 2005;48:1-9.

7 Rivera MP. Lung cancer in women: differences in epidemiology, biology, histology, and treatment outcomes. Semin Respir Crit Care Med 2013;34:792-801.
8 Pierce JP, Messer K, James LE, et al. Camel No. 9 cigarettemarketing campaign targeted young teenage girls. Pediatrics 2010;125:619-26.

9 Carpenter CM, Wayne GF, Connolly GN. Designing cigarettes for women: new findings from the tobacco industry documents. Addiction 2005;100:837-51.

10 Doxey J, Hammond D. Deadly in pink: the impact of cigarette packaging among young women. Tob Control 2011;20:353-60.

11 Huxley RR, Woodward M. Cigarette smoking as a risk factor for coronary heart disease in women compared with men: a systematic review and meta-analysis of prospective cohort studies. The Lancet 2011:378:1297-305.

12 Gaudet MM, Gapstur SM, Sun J, et al. Active smoking and breast cancer risk: original cohort data and meta-analysis. J Natl Cancer Inst 2013;105:515-25.

13 Pierce JP, Patterson RE, Senger CM, et al. Lifetime cigarette smoking and breast cancer prognosis in the after breast cancer pooling project. J Natl Cancer Inst 2014;106:djt359.

14 Roura E, Castellsagué X, Pawlita M, et al. Smoking as a major risk factor for cervical cancer and pre-cancer: results from the EPIC cohort. Int J Cancer 2014;135:453-66.

15 Bolumar F, Olsen J, Boldsen J, et al. Smoking reduces fecundity: a European multicenter study on infertility and subfecundity. $\mathrm{Am} J$ Epidemiol 1996;143:578-87.

16 Caserta D, Bordi G, Di Segni N, et al. The influence of cigarette smoking on a population of infertile men and women. Arch Gynecol Obstet 2013;287:813-8.

17 Taal HR, de Jonge LL, van Osch-Gevers L, et al. Parental smoking during pregnancy and cardiovascular structures and function in childhood: the generation R study. Int J Epidemiol 2013;42:1371-80.

18 Horta BL, Victora CG, Menezes AM, et al. Low birthweight, preterm births and intrauterine growth retardation in relation to maternal smoking. Paediatr Perinat Epidemiol 1997;11:140-51.

19 Hayatbakhsh MR, Clavarino A, Williams GM, et al. Cigarette smoking and age of menopause: a large prospective study. Maturitas 2012;72:346-52.

20 Cornuz J, Feskanich D, Willett WC, et al. Smoking, smoking cessation, and risk of hip fracture in women. $A m \mathrm{~J}$ Med 1999;106:311-4.

21 Kanis JA, Johnell O, Odén A, et al. Smoking and fracture risk: a meta-analysis. Osteoporos Int 2005;16:155-62.

22 Kaleta D, Usidame B, Polańska K. Tobacco advertisements targeted on women: creating an awareness among women. Cent Eur J Public Health 2011;19:73-8.

23 Bohadana A, Nilsson F, Rasmussen T, Martinet Y, et al. Gender differences in quit rates following smoking cessation with combination nicotine therapy: influence of baseline smoking behavior. Nicotine Tob Res 2003;5:111-6.

24 Benowitz NL. Clinical pharmacology of nicotine: implications for understanding, preventing, and treating tobacco addiction. Clin Pharmacol Ther 2008;83:531-41.

25 Benowitz NL, Lessov-Schlaggar CN, Swan GE, et al. Female sex and oral contraceptive use accelerate nicotine metabolism. Clin Pharmacol Ther 2006;79:480-8.

26 Piper ME, Cook JW, Schlam TR, et al. Gender, race, and education differences in abstinence rates among participants in two randomized smoking cessation trials. Nicotine Tob Res 2010;12:647-57.

27 Perkins KA, Scott J. Sex differences in long-term smoking cessation rates due to nicotine patch. Nicotine Tob Res 2008;10:1245-50.

28 Weinberger AH, Smith PH, Allen SS, et al. Systematic and metaanalytic review of research examining the impact of menstrual cycle phase and ovarian hormones on smoking and cessation. Nicotine Tob Res 2015;17:407-21.

29 McVay MA, Copeland AL. Smoking cessation in peri- and postmenopausal women: a review. Exp Clin Psychopharmacol 2011;19:192-202.

30 Leventhal AM. The sociopharmacology of tobacco addiction: implications for understanding health disparities. Nicotine Tob Res 2016;18:110-21.

31 Smith $\mathrm{PH}$, Bessette AJ, Weinberger $\mathrm{AH}$, et al. Sex/gender differences in smoking cessation: a review. Prev Med 2016;92:135-40.

32 Breiding MJ, Smith SG, Basile KC. Prevalence and characteristics of sexual violence, Stalking, and intimate partner violence victimization-National intimate partner and sexual violence survey, United States, 2011. Am J Public Health 2015;105:e11-12.

33 Kristman-Valente AN, Brown EC, Herrenkohl TI. Child physical and sexual abuse and cigarette smoking in adolescence and adulthood. $J$ Adolesc Health 2013:53:533-8. 
34 Hayes J. Women's Median Earnings as a Percent of Men's Median Earnings, 1960-2009 (Full-Time, Year-Round Workers) with Projection for Pay Equity in 2056. 4. IWPR Publication Q, 2011.

35 al'Absi M, Nakajima M, Allen S, et al. Sex differences in hormonal responses to stress and smoking relapse: a prospective examination. Nicotine Tob Res 2015;17:382-9.

36 Ferguson SG, Frandsen M, Dunbar MS, et al. Gender and stimulus control of smoking behavior. Nicotine Tob Res 2015;17:431-7.

37 Chaney SE, Sheriff SW, Merritt L. Gender differences in smoking behavior and cessation. Clin Nurs Stud 2015;3:17-22.

38 Harris KK, Zopey M, Friedman TC. Metabolic effects of smoking cessation. Nat Rev Endocrinol 2016;12:299-308.

39 Allen AM, Oncken C, Hatsukami D. Women and smoking: the effect of gender on the epidemiology, health effects, and cessation of smoking. Curr Addict Rep 2014;1:53-60.

40 Jarvis MJ. The association between having children, family size and smoking cessation in adults. Addiction 1996;91:427-34.

41 Celik H, Lagro-Janssen TALM, Widdershoven GGAM, et al. Bringing gender sensitivity into healthcare practice: a systematic review. Patient Educ Couns 2011;84:143-9.

42 Vos HMM, Schellevis FG, van den Berkmortel H, et al. Does prevention of risk behaviour in primary care require a gender-specific approach? A cross-sectional study. Fam Pract 2013;30:179-84.

43 Jayakumar $\mathrm{N}$, Chaiton M, Zhang B, et al. Sex differences in use of smoking cessation services and resources: a real-world study. Tob Use Insights 2020;13:1179173X2090150.

44 Torchalla I, Okoli CTC, Bottorff JL, et al. Smoking cessation programs targeted to women: a systematic review. Women Health 2012;52:32-54.

45 Braun V, Clarke V. Using thematic analysis in psychology. Qual Res Psychol 2006;3:77-101.

46 Council, N. B. Public health: ethical issues. London: Nuffield Council on Bioethics, 2007

47 Wray JM, Gray KM, McClure EA, et al. Gender differences in responses to cues presented in the natural environment of cigarette smokers. Nicotine Tob Res 2015;17:438-42.

48 Tomko RL, Saladin ME, Baker NL, et al. Sex differences in subjective and behavioral responses to stressful and smoking cues presented in the natural environment of smokers. Nicotine Tobacco Research 2020;22:81-8.
49 Perkins KA, Karelitz JL, Giedgowd GE, et al. Negative mood effects on craving to smoke in women versus men. Addict Behav 2013;38:1527-31.

50 Xu J, Azizian A, Monterosso J, et al. Gender effects on mood and cigarette craving during early abstinence and resumption of smoking Nicotine Tob Res 2008;10:1653-61.

51 Weinberger AH, Pittman B, Mazure CM, et al. A behavioural smoking treatment based on perceived risks of quitting: a preliminary feasibility and acceptability study with female smokers. Addict Res Theory 2015;23:108-14.

52 Westmaas JL, Wild TC, Ferrence R. Effects of gender in social control of smoking cessation. Health Psychol 2002;21:368-76.

53 Martin JL, Barnes I, Green J, et al. Social influences on smoking cessation in mid-life: prospective cohort of UK women. PLoS One 2019;14:e0226019.

54 Park EW, Schultz JK, Tudiver FG, et al. Enhancing partner support to improve smoking cessation. Cochrane Database Syst Rev 2018. (3).

55 Schoenaker DAJM, Brennan E, Wakefield MA, et al. Anti-Smoking social norms are associated with increased cessation behaviours among lower and higher socioeconomic status smokers: a population-based cohort study. PLoS One 2018;13:e0208950.

56 Minian N, Penner J, Voci S, et al. Woman focused smoking cessation programming: a qualitative study. BMC Womens Health 2016;16:17.

57 Farley AC, Hajek P, Lycett D, et al. Interventions for preventing weight gain after smoking cessation. Cochrane Database Syst Rev 2012;1:CD006219.

58 VNN. Vergoeding opname rokers in verslavingskliniek, 2019. Available: https://www.vnn.nl/kennisbank/nieuws/vergoedingopname-rokers-verslavingskliniek [Accessed 3 Jan 2019].

59 Kelly JF, Greene MC, Bergman BG. Recovery benefits of the "therapeutic alliance" among 12-step mutual-help organization attendees and their sponsors. Drug Alcohol Depend 2016;162:64-71.

60 Clements-Thompson M, Klesges RC, Haddock K, et al. Relationships between stages of change in cigarette smokers and healthy lifestyle behaviors in a population of young military personnel during forced smoking abstinence. J Consult Clin Psychol 1998;66:1005-11.

61 Patten C, Wang X-Q, Ebbert JO, et al. Influence of gender and peer tobacco use on tobacco use intentions after a period of involuntary tobacco abstinence among U.S. air force trainees. Prev Med Rep 2019;13:270-6. 